\title{
ANAK USIA 6 TAHUN HARUS BISA MENENUN Kesepakatan Adat Suku Sabu dan Stimulasi Perkembangan Anak Usia Dini
}

\author{
Beatriks N. Bunga \\ Fakultas Ilmu Pendidikan, Universitas Nusa Cendana Kupang \\ Email: beatriksbunga17@gmail.com
}

\begin{abstract}
This research explains about local agreement and how the relationship with stimulation of Development for early Children. This research results show woman/mother in the Sabu tribe always bring the Children and involved them on simple working. There ari 8 steps on weave which have a relation with stimulation of Children Development like spin cotton into yarn, ta war'ru wang'gu, ta mane, ta tali wangg'gu, ta hab 'bu, introduction of evaporation concept with Sun and windu, ta hap'pu, dan ke'jeri.
\end{abstract}

Keyword: Local Agreement, Early Child Developmental Stages

\begin{abstract}
Abstrak
Studi ini menjelaskan tentang kesepakatan lokal dan bagaimana hubungannya dengan stimulasi perkembangan anak usia dini. Hasil penelitian menunjukkan bahwa perempuan/ ibu di suku Sabu selalu membawa anaknya dan melibatkan mereka dalam pekerjaan sederhana. Ada delapan tahap dalam menenun yang memiliki hubungan dengan stimulasi perkembangan anak, yaitu proses memintal kapas menjadi benang, ta war'ru wang'gu, ta mane, ta tali wangg'gu, ta hab 'bu, pengenalan konsep penguapan dengan matahari dan angin, ta hap'pu, dan ke'jeri
\end{abstract}

Keyword: kesepakatan lokal, tahap perkembangan anak usia dini

\section{PENDAHULUAN}

Penelitian ini dibuat sebagai suatu langkah awal untuk menjawab persoalan mengenai eksistensi PAUD di NTT. Berdasarkan hasil laporan kebijakan PAUD 2011 (Dirjen PAUD, 2011) NTT adalah propinsi dengan angka Partisipasi Sekolah paling rendah di Indonesia. Angka ini memang jauh berada di bawah APK Nasional yaitu 27,31dari 53,70 \%. Ada beberapa penyebab yang dipaparkan yaitu proses pembelajaran masih diwarnai oleh CALISTUNG, Kuali-fikasi Pendidik yang masih belum memadai, kompetensi pendidik (pelatihan yang diikuti) masih rendah, jumlah PAUD rujukan yang masih terbatas. Survai yang dilakukan Labre, dkk (2011) di Kab Sikka dan Labre dkk (2011) di Kabupaten TTU mempertegas angka yang dilaporkan sebelumnya.

Secara kualitatif survai ini menunjuk-kan di Kab Sikka dan di Kab TTU bahwa jumlah PAUD yang masih aktif tidak sampai 20, sisanya tidak aktif lagi; kualifikasi pendidikan rata-rata adalah SMA bahkan ada yang SMP, pendidikan dan pelatihan yang tidak diterima oleh tutor atau guru sehingga mempengaruhi kemampuan mereka menga-jar. Survai yang dilakukan Bunga (2011) di Kabupaten Belu menambahkan satu faktor mengapa APK dan ketidakaktifan PAUD yaitu karena partisipasi masyarakat seperti tidak pedulinya orang tua terhadap PAUD sehingga lebih memilih memasukan anak di SD saat umur 5-6 tahun, tidak ada rasa memiliki terhadap lembaga PAUD sehingga fungsi kontrol terhadap keberlangsungan PAUD tidak terjadi.

Kondisi di atas berakhir pada sebuah kesimpulan bahwa perlu ada model sosialisasi PAUD dan pemberdayaan PAUD yang me-nyentuh nilai-nilai lokal NTT. Kualitas SDM di NTT belum siap dan 
mampu mener-jemahkan konsep-konsep PAUD serta model-model PAUD yang ditawarkan dari tanah seberang. Penelitian yang dilakukan di Bots-wana mengenai Early Childhood Care and Education in Africa (Bar-On, 2004) memper-lihatkan bahwa budaya sangat mempengaruhi pola pikir masyarakat Afrika terhadap pengembangan ECCE. Orang tua di Afrika ingin budaya mereka tetap terpelihara dalam model pengasuhan pendidikan anak usia dini mereka. Apa yang baik menurut dunia barat, belum tentu baik untuk budaya di Afrika. Untuk itu perlu ada nilai-nilai lokal yang harus di kembangkan agar PAUD dan model pembelajaran PAUD dapat menetap di NTT.

Penelitian-penelitian yang menggali potensi budaya dalam rangka pengembangan pendidikan mulai banyak dilakukan di Indonesia. Seriati (2010) mengidentifikasi ada 57 permainan gerak dan lagu di Yogyakarta yang mengandung nilai-nilai edukasi. Selanjutnya Seriati mengangkat 7 model permainan tradi-sional gerak dan lagu jawa yang memiliki nilai-nilai edukatif yang cocok untuk anak PAUD. Menurutnya permainan tradisional dapat menjadi model untuk pengembangan kemampuan sosial anak seperti mau berbagi, empati, tanggung jawab sosial, mampu dapat mengontrol diri dalam konflik. Hasil peneli-tian Astuti (2010) menunjukkan bahwa cerita fiksi dalam cerita tradisional meningkatkan kemampuan bahasa anak. Suharyani (2010) menambahkan dalam hasil penelitiannya bahwa permainan tradisional berhitung dapat mengembangkan kemampuan sosial anak. Menurut Iswinarti (2010) permainan tradisional engklek mampu meredakan ketegangan-ketegangan dalam diri anak sehingga mem-buat anak sehat secara mental. Lanjut dikata-kan bahwa permainan engklek mengandung nilai sosial yang mengajarkan anak bertang-gung jawab dan menghargai orang lain. Bunga (2012) mengidentifikasi hampir 67 per-mainan tradisional yang ada di NTT. Permainan tradisional itu menawar-kan nilai-nilai pengembangan karakter dalam permainan tradisional di NTT seperti nilai kecintaan kepada tanah air, nilai kebangsaan, nilai kecintaan terhadap lingkungan, nilai kerjasama, tanggung jawab, dan penghargaan.

Menurut Bunga unsur-unsur lokal inilah yang sebenarnya harus digali dan dipakai dalam proses pembelajaran PAUD di NTT karena lebih dikenal oleh masyarakat dan lebih mengikat masyarakat untuk berpartisipasi dalam pendidikan anak pada usia dini.

NTT adalah wilayah kepulauan. Ada kurang lebih 111 pulau ada di NTT. Pulaupulau besar di antaranya adalah pulau Flores, Pulau Sumba dan Pulau Timor, sedangkan pulau-pulau kecil diantaranya pulau Sabu, Pulau Rote, Pulau Ndao, Pulau Semau, Pulau Alor, Pulau Pantar, Pulau Pura, Pulau Lembata, Pulau Solor, Pulau Adonara, Pulau Palue, Pulau Babi, Pulau Permana, Pulau Komodo dan Pulau Rinca. Pulau-pulau ini masih bersifat tradisional, meskipun ada beberapa pulau yang pembangunan dan informasi berkembang pesat. Bersifat tradisional karena masih banyak nilai-nilai adat atau kesepakatan-kesepakatan adat yang dipakai sebagai rambu-rambu lalu lintas untuk mengatur kehidupan masyarakat di pulau tersebut. Menurut Koentjaraningrat (1972) nilai-nilai lokal yang diyakini kebenarannya akan dipakai sebagai pedoman perilaku di tempat ia tumbuh.

Pulau Sabu adalah salah satu pulau yang masih bersifat tradisional. Ada banyak kesepakatan-kesepakatan adat yang menggunakan tradisi lisan yang turun-temurun masih digunakan dan dijaga. Kesepakatankesepakatan yang diturunkan secara lisan ini dipakai sebagai nilai-nilai hidup atau karakteristik orang dari pulau ini atau biasa dikenal dengan Orang Sabu. Menurut Riwu Kaho (2005) adat istiadat baik lisan maupun tertulis bagi orang Sabu adalah sama dengan syariat agama dan hukum agama. Selanjutnya orang Sabu boleh berbeda pendapat, akan tetapi jika itu menimbulkan perseteruan dipandang salah. Harus dicari penyelesaiannya dan adat istiadat serta kesepakatan tua-tua adat menjadi tolak 
ukurnya. Inilah yang disebut toleransi dalam kehidupan orang Sabu

Salah satu kesepakatan adat yang diatur dalam suku Sabu adalah mengenai Pendidikan Anak. Orang tua di Sabu secara turun temurun tidak memiliki metode khusus mengajarkan nilai-nilai hidup pada anak mereka. Tradisi lisan dan praktek langsung menjadi metode nya. Anak-anak selalu diajak dalam setiap jenis pekerjaan yang dilakukan orangtuanya, dan pada saat itulah orangtua akan bercerita tentang nilai-nilai menjadi orang Sabu. Diketahui bahwa kepercayaan dan nilai-nilai hidup di turunkan orang tua kepada anak tidak hanya melalui kata-kata tetapi lewat pemodelan orangtua (Siegel, 1997) dan praktik langsung (Gottfried et al. 1998). Termasuk dalam menenun. Menenun bagi orang Sabu adalah sebuah kewajiban. Semua perempuan dewasa dan remaja bisa menenun, bahkan sejak anak-anak sudah diajar menenun (Pos Kupang, 2011).

Penulis mengamati r bahwa
sebenarnya ada stimulasi tahapan
perkembangan anak yang terjadi ketika anak
melakukan proses penenun. Untuk
mensosialisasikan bahwa ada potensi budaya
yang dapat dipakai dalam proses pembelajaran, tentunya kita harus memahami nilai-nilai dan kepercayaan yang terkandung dalam budaya setempat (Deldago dan Ford, 1998; Gutman dan Mcloyd 2000; Bornstein dan Cote 2004).

Penelitian tentang ada unsur stimulasi tahapan perkembangan dalam tahapan menenun belum pernah dilakukan sebelum-nya di NTT. Untuk itu penulis ingin menggali lebih dalam mengenai Kesepakatan Adat mengenai Anak Usia 6 tahun harus bisa menenun: Proses pembuatan tenun ikat Sabu terkait dengan stimulasi tahapan perkembang-an anak usia dini.

\section{METODOLOGI PENELITIAN}

Untuk menggali data tentang kesepakatan-kesepakatan adat Sabu, maka 3 informan kunci di pilih untuk berbagi informasi (Umur 71 tahun, 72 tahun dan 74 tahun). Informan di pilih adalah mereka yang lahir dan besar di Sabu, mereka dikenal sebagai tokoh adat di Kota Kupang, memahami proses tenun ikat Sabu. Rata-rata umur informan adalah 70 tahun (71 tahun, 72 tahun dan 74 tahun), berjenis kelamin laki-laki 2 orang dan 1 perempuan.

Tabel 1. Karakteristik Partisipan

\begin{tabular}{|c|c|c|}
\hline Umur & $\begin{array}{l}\text { Jenis } \\
\text { Kelamin }\end{array}$ & Level Pemahaman tentang Sabu \\
\hline \multirow[t]{6}{*}{71 tahun } & \multirow[t]{6}{*}{ Laki-laki } & $\begin{array}{l}\text { - Menulis Skipsi } \text { tentang Tinjauan } \\
\text { Historis tentang masyarakat pulau } \\
\text { Sabu, } 1973\end{array}$ \\
\hline & & $\begin{array}{ccc}\text { - Kepala Museum } & \text { Propinsi } & \text { Kota } \\
\text { Kupang tahun } 1986 & & \end{array}$ \\
\hline & & $\begin{array}{lcc}\text { - Kepala Bidang } & \text { Sejarah } & \text { dan } \\
\text { Permuseuman tahun } & \text { 1992-1997 }\end{array}$ \\
\hline & & $\begin{array}{l}\text { - Tim penulis buku Perlengkapan } \\
\text { Busana dan Perhiasan Pengantin Suku }\end{array}$ \\
\hline & & $\begin{array}{l}\text { Tetun dan Sabu 1989, Proyek } \\
\text { Pengembangan Museum }\end{array}$ \\
\hline & & $\begin{array}{l}\text { - Tim ahli kebudayaan NTT di RRI Kota } \\
\text { Kupang, 2011-sekarang }\end{array}$ \\
\hline 73 tahun & Laki-laki & $\begin{array}{l}\text { - Tokoh adat urusan perkawinan Sabu di } \\
\text { Kupang. Selalu menjadi JURU } \\
\text { BICARA adat di acara Adat Sabu }\end{array}$ \\
\hline
\end{tabular}


Jurnal Parameter Volume 29 No. 2

DOI : doi.org/10.21009/parameter.292.04

P-ISSN : 0216-26IX

\begin{tabular}{|l|l|l|}
\hline 74 tahun & Perempuan & $\begin{array}{l}\text { - Memiliki usaha tenun ikat } \\
\text { - Beberapa kali menjadi perwakilan } \\
\text { pengusaha Tenun Ikat Sabu di Jakarta }\end{array}$
\end{tabular}

\section{A. Pengumpulan Data dan Prosedur}

Pengumpulan data dilakukan dengan

teknik wawancara yang terbagi atas 3

langkah:

Mengidentifikasi tentang beberapa kesepakatan adat Sabu

Kesepakatan adat mengenai "anak harus bisa menenun saat

umur 6 tahun"

Membandingkan tahapan menenun dengan model stimulasi perkembangan anak usia dini

Bagan 1. Langkah-Langkah Teknik Wawancara

Hasil interview dianalisis secara kualitatif dengan pendekatan Etnografi. Garfinkel (Bungin, 2001) adalah orang pertama yang mencetus ide mengenai etnometodologi. Metode ini mengacu pada studi mengenai seorang individu dalam masyarakt bertindak dan berkreasi serta memahami hidup keseharian. Malinowski (Bungin, 2001) seorang antropolog mengatakan bahwa tujuan dari studi ini adalah untuk memahami pandangan masyarakat setempat, tentang bagaimana relasinya dan visinya terhadap kehidupan dan dunia. Spadley (Bungin, 2001) mengatakan bahwa etnografi ingin belajar dari masyarakat dan ingin mengetahui bagaimana masyarakat itu sendiri memberi konsep tentang dunia yang sedang mereka jalani, tindakan apa saja yang dilakukan dalam merespons lingkungan dimana mereka hidup, jadi bukan menurut konsep dan tafsir peneliti.

Dalam penelitian ini kehidupan masyarakat Sabu terkait dengan kesepakatan-kesepakatan adat, terutama mengenai anak umur 6 tahun harus mampu menenun dan bagaimana kesepakatan itu mengandung nilai stimulasi dini tahapan perkembangan anak.

\section{HASIL DAN PEMBAHASAN}

A. Gambaran Pulau Sabu Raijua

\section{Letak Geografis}

Kepulauan Sabu terletak diantara pulau Sumba, pulau Rote dan Pulau Timor pada $121^{\circ} 45^{\prime}$ sampai $122^{\circ}-4^{\prime} \mathrm{BT}$ dan $10^{\circ} 27^{\prime}$ sampai $10^{\circ} 38^{\prime} \mathrm{LS}$. Kepulauan ini terdiri atas 3 pulau yaitu Pulau Sabu, Pulau Rai jua dan Pulau Dana. Hanya saja menurut informasi dikatakan bahwa Pulau Dana tidak 
berpenduduk. Dahulunya pulau ini diceritakan sebagai tempat tinggal pengeran Majapahit yang menikah dengan salah satu wanita Sabu dari Raijua. Pulau ini kemudian diguna-kan oleh orang-orang keturunan Majapahit melakukan upacara adat pascapanen untuk memperingati pangeran. Luas pulau Sabu seluruhnya adalah $602 \mathrm{~km}^{2}$. Sekarang pulau ini sudah otonomi sendiri menjadi Kabupaten Sabu Raijua.

\section{Keadaan Alam dan Iklim}

Kepulauan Sabu terdiri dari tanah dataran rendah dan berbukit-bukit. Hampir semua bagian pulau ini terdiri dari tanah putih/ kapur dan tanah merah yang kurang mata pencaharian penduduk. Mereka mengan-dalkan hujan untuk bertani juga menyadap nira. Pohon nira adalah salah satu jenis palam yang banyak tumbuh di daerah tandus dan kering seperti sabu. Air sadapan subur. Keadaan ala mini relatif sama di semua daerah Sabu hanya bagian utara yang relatif lebih hijau karena ada sejumlah mata air dan sungai yang berair sepanjang tahun. Sementara di bagian selatan kering dan tandus bahkan tidak memiliki mata air.

Keadaan iklim Sabu ditandai dengan musim kemarau yang panjang yang berlangsung dari bulan Maret-November. Musim hujan hanya terjadi selama 3 bulan saja.

\section{Mata Pencaharian}

Karena iklim di pulau Sabu yang kurang mendukung, maka berpengaruh pada

nira kemudian diolah menjadi beberapa makan lokal sabu yang dikenal dengan gula sabu. Penduduk Sabu juga memanfaatkan laut sebagai salah satu mata pencaharian mereka

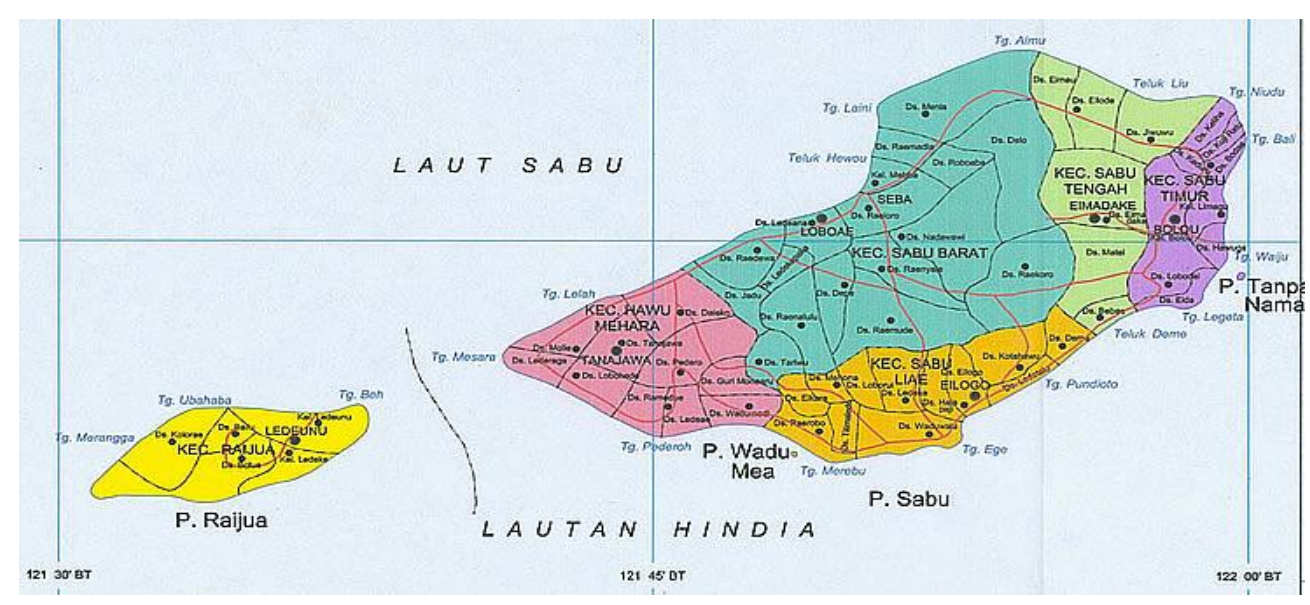

Gambar 1. Peta Pulau Sabu

\section{B. Kesepakatan Adat Sabu "Anak Usia Usia 6 Tahun Harus Bisa Menenun"}

Kesepakatan Adat menurut informan adalah ide-ide bersama yang di sepakati sejak leluhur kemudian diturunkan secara turun temurun dan dipercaya menjadi aturan yang harus dilaksanakan. Kesepakatan adat ini dulunya dibuat oleh para tua-tua adat dan biasanya akan mengundang seluruh anggota keluarga sampai pada keturunan ke-3 generasi tersebut untuk memecahkan suatu masalah. Karena ini dibuat oleh tua-tua adat, sifatnya kesepakatan adat ini dianggap mengikat. Awalnya ini hanya merupakan kesepakatan untuk mengatur kehidupan masyarakat, akan tetapi karena dilakukan secara turun-temurun, kesepakatan ini kemudian menjadi norma-norma yang dipakai sampai sekarang. Misalnya dalam hal gotong royong dalam membangun rumah adat. Orang Sabu dikenal oleh suku lain dengan semangat gotong royong ini.

Kesepakatan adat dalam hal gotong royong membangun Rumah Adat misalnya. 
Semua keluarga mulai dari generasi 1generasi ketiga berkumpul di rumah orang tertua. Di situ akan dibicarakan semua hal dari menyiapkan bahan dan bagaimana mendapatkannya. Semua anggota keluarga yang ada mendapat tugas. Pembagian tugas ini di pun dibagi berdasarkan keturunan dan jenis kelamin. Misalnya keturunan yang berasal dari perempuan biasanya diberi tugas untuk menyediakan beras. Semua orang diberi tanggung jawab dan harus melaksana-kan tugasnya. Jika tidak, sanksi adat tidak di sepakati tetapi, karena ini dianggap kesepakatan Adat sehingga sanksinya berupa sakit penyakit dan bencana bagi keluarga yang tidak melakukan tanggung jawabnya".

Contoh kesepakatan lain adalah adat pergaulan. Orang Sabu diharapkan harus menyapa dengan sapaan-sapaan khusus. Sapaan ini sudah dibiasakan oleh orang tua kepada anaknya sejak anak itu mulai mengenal keluarganya. Sapaan ini menjadi satu model kesepakatan adat yang menjadi nilai orang Sabu. Sapaan ini menjadi ciri khas yang melekat dimanapun, walaupun sudah ada proses kawin mawin dengan suku lain dan walaupun orang Sabu sudah pindah bahkan menetap di negeri lain.

Sapaan pada orang Sabu selalu di lihat dari tingkat umur. Ini berlaku seumur hidup, walaupun ia sudah menikah dengan suku lain dan sudah pindah tinggal di tempat lain. Orang Sabu biasa dikenal dengan panggilan Ina untuk perempuan, dan Ama panggilan untuk laki-laki.

Ibu dipanggil Ina, Bapa dipanggil Ama; saudara perempuan ibu yang lebih tua dipanggil Ina Ae, yang lebih muda dipanggil Ina Kue, Saudara ibu yang laki-laki disebut Ma Kemone. Saudara bapak yang kakak dipanggil Ama Ae, yang adik dipanggil Ma Iki. Saudara perempuan dipanggil Ana Wanni, yang lebih muda dipanggil $\mathrm{Na}$ Wanni/ Benni Ari dan yang lebih tua dipanggil Na Wanni/Benni Aa. Nenek Pria dipanggil Apu Mone, nenek wanita dipanggil Appu Benni. Cucu pria dan wanita dipanggil juga $A p p u$ Monne dan Appu Benni.

Sapaan ini di tuntut harus dipahami oleh tiap lapisan generasi. Ketika salah menyapa sesuai tingkatan generasi, akan di marahi oleh yang tua dan di beri penjelasan secara silsilah. Panggilan umum Ama dan Ina ini sudah menjadi ciri khas orang Sabu. Jika perkenalan pertama orang mengenal kan diri sebagai orang Sabu, maka otomatis setelah perkenalan itu, dia akan langsung di sapa dengan Ina atau Ama.

Kesepakatan Ada yang berikut adalah mengenai menenun. Orang Sabu khususnya perempuan harus bisa menenun. Ukuran kecantikan seorang perempuan di ukur dari terampil tidaknya perempuan itu menenun. Semakin terampil, semakin di sukai oleh kaum pria. Dan proses pembelajaran tenun ini sudah dilakukan orangtua (Ina) sejak anak-anak. Pembagian tugas di Suku Sabu bersifat patriakhat, yaitu anak laki-laki akan mengikuti ayahnya untuk berkerja dan anak perempuan bersama sang ibu.

Di Sabu, menenun itu wajib bagi kaum perempuan. Perempuan dikatakan cantik jika dia mampu menenun dengan baik. Sebaliknya, perempuan yang tidak bisa menenun dianggap sebagai wanita yang malas, bukan calon ibu rumah tangga yang baik. Ada pepatah begini gaga benni dao, paku kuta nga ai medi. Pepatah ini sebenarnya adalah sebuah pujian di diberikan pada anak yang sudah pintar menenun. Arti pujian ini adalah anak perempuan yang tangan selalu hitam, memakai sarung hitam, akan bertambah cantik.

Kemampuan menenun ini merupakan kesepakatan adat tidak tertulis. Begitu seorang anak lahir dan diketahui berjenis kelamin perempuan, saat itu juga kesepakatan adat itu melekat pada bayi tersebut. 
Bahkan sejak bayi anak mulai mulai diperkenalkan dengan tenun. Tempat ayunan bayi biasa di gantung di tempat menenun ibu. Ketika anak bermain bermain di biarkan bermain di tikar tempat ibu menenun. Jika anak mena-ngis, ibu-ibu menghiburnya dengan membunyikan alat-alat tenun atau membiarkan alat-alat tenun seperti kabba wanggu di pegang anak, kedia di putarputar. Memberi makan anak pun di tempat mereka mengerjakan tenunnya.

Orang tua selalu mengajak anaknya (sebelum usia SD) untuk bekerja misalnya ke ladang dan mengiris tua, sedangkan anak perempuan piko aer dan menenun. Anak diajak bermain-main dekat tempat ama atau ina bekerja sebagai bentuk sosialisasi"

"Tidak ada waktu belajar khusus untuk mengajar anak perempuan menenun. Mengajak mereka saat bekerja adalah bentuk mengajar bagi orang tua di Sabu. Tetapi sekarang sudah ada program PAUD di Sabu sehingga anak-anak usia itu sudah mulai belajar di PAUD.

\section{Tahapan Tenun Ikat Sabu dan Stimulasi Tahapan Perkembangan Anak}

Ada beberapa tahap dalam tenun yang perlu diperhatikan. Dimulai dengan memintal kapas menjadi benang dengan alat sederhana. Hasil pintalan kemudian akan digulung. Selanjutnya benang harus direntangkan untuk di ikat sesuai motif yang diinginkan. Tali yang dipakai untuk mengikat adalah daun lontar.

Proses selanjutnya dicelup kedalam warna-warna yang bahannya diambil langsung dari alam. Setelah itu ikatan daun lontar tadi di buka dan dicelup kewarna yang berbeda sehingga bunga dari ikatan itu tampak. Setelah itu dijemur. Jika benang itu sudah kering, maka benang sudah bisa diatur ke alat tenun. Alat tenun yang digunakan sangat sederhana, hanya berupa sebilah pedang, dua batang bambu atau kayu, mata pintal dan ikat pinggang.

\section{Tahap manga'ri wang'gu}

Saat proses pengumpulan kapas dari pohonnya, anak-anak usia 3-5 tahun biasanya diajak orang tuanya ke ladang. Anak-anak suka kegiatan ini, karena mereka bisa berlari-lari dan berebutan mengambil kapas dan mengumpulkan dalam nyiru. Proses ini disebut pui wanggu.

Saat mengumpulkan kapas anak-anak tidak dipaksa untuk melakukannya, jika mereka ingin bermain atau berlari-lari saja, tidak masalah.

Setelah di kumpulkan, kapas akan dikeluarkan dari bijinya dengan menggunakan alat yang bernama manggari yang terbuat dari kulit penyu dan kayu bulat. Saat mengeluarkan biji anak-anak juga ikut membantu. Anak-anak yang besar umur 6-7 tahun biasa diberi alat manggari.

Pada proses manggari anak harus menggulung kayu bulat tersebut untuk mengeluarkan biji kapas. Anak. Setelah dikeluarkan dari biji, kapas di atur di tikar untuk di lakukan proses buhu. Buhu adalah benda seperti busur yang akan ditarik senarnya dekat kapas yang diatur di tikar supaya melekat pada tali busur.

Setelah itu akan di putar dengan haru. Alat kecil ini seperti gasing, akan berputar dan benangnya akan di putar. Orangtua biasa meminta anak yang kecil-3-6 tahun untuk memutar haru karena saat proses haru ibu berdiri dan tangannya harus diangkat tinggi, sehingga untuk duduk dan berdiri akan membuat benang menjadi kusut, sehingga membutuhkan bantuan.

Tahap berikut dalah di lore. Alat lore berupa kayu yang berbentuk huruf $\mathbf{H}$. Benang akan dililit di dua sisi.

Pada proses ini dapat dipahami ada proses stimulasi tahapan perkembangan anak usia yaitu menstimulasi fisik motorik halus pada saat anak memetik kapas, anak dapat membedakan antara kapas yang halus dan 
daunnya yang kasar. Motorik kasar, yaitu saat anak menggulung kayu untuk mengeluarkan biji kapas. Koordinasi tangan anak untuk membuat gerakan maju mundur juga melatih anak untuk membedakan konsep kata berlawanan. Pada saat memutar haru, ada koordinasi motorik anak untuk membuatnya berputar seperti gasing. Pada saat yang sama juga anak dilatih untuk mengenal bagian-bagian tumbuhan bahwa ada batang, ada daun dan ada bunganya. Proses ini juga memberi efek relaksasi pada anak karena anak berlari-lari dan tertawa saat berebutan mengambil kapas.

\section{E. Tahap Ta Wa'rru Wa'nggu}

Benang di keluarkan dari lore dan diatur di alat yang namanya Ke'dia. Alat ini berupa 4 alat kris yang dimasukan secara bersilang dalam kayu penopangnya.

Benang akan di gulung menjadi bulatan-bulatan seperti seperti bolabola kecil

Benang yang digulung biasanya berwarna-warni.

Biasanya anak-anak usia 4-6 tahun sudah mulai diajar untuk menggulungnya.

Anak-anak yang lebih kecil bayi-2 tahun, menggunakan bola warna warni itu untuk bermain.

Pada tahap ini anak distimulasi motorik halusnya. Anak mulai menggulung dari sebuah gulungan kecil menjadi gulungan besar. Otot-otot jarinya harus berkoordinasi dengan baik untuk mendapat menggulung agar pas dan menjadi bulat. Pada saat yang sama juga anak mampu membedakan konsep besar dan kecil. Warnawarna benang juga menstimulus anak mengenal warna.

\section{F. Tahap ta mane}

Bulatan benang akan direntang di sebuah alat. Bulatan benang ditaruh dalam sebuah mangkuk yang terbuat dari tempurung kelapa atau $k a{ }^{\prime} b b a$ wa'nggu. Ini dilakukan dengan bantuan anak. Ini dapat dilakukan oleh anak 3-6 tahun. Anak berada di tengah membantu menghantar bulatan benang antara orang 1 dan kedua.

Biasanya ada 2 anak yang membantu. Anak yang remaja berada di bagian atas karena benang harus dikumpulkan sebanyak 7 urat dan disatukan.

Pada tahap ini anak motorik kasar dan halus anak di stimulus. Gesekan tangan anak dengan benang menstimulus indera peraba anak untuk membedakan konsep gesekan. Putaran benang pada ka'bba wa'nggu mengajarkan konsep putaran. Mengumpulkan benang sebanyak 7 helai adalah stimulasi kemampuan membilang angka 1-7 bagi AUD.

\section{G. Tahap ta tali wang'gu}

Ta tali wang'gu artinya di ikat. Benang yang sudah di mane tadi dipindahkan kea lat untuk mengikat. Benang yang dipisahkan setiap 7 helai benang itu akan diikat sesuai dengan motif dalam contoh gambar.

Biasanya anak usia remaja yang mengerjakan ini.

Saat orang tua mengikat benang, biasanya anak mereka yang berusia 57 tahun akan dilatih mengikat di tempat yang kosong.

Saat mengajarkan anak mengikat, orang tua akan menerangkan sebaiknya diikat berapa kali putaran dan perlu dikencangkan.

Ikatan tali menggunakan daun lontar.

Pada tahap ini kemampuan seni anak dilatih karena anak dilatih untuk melihat gambar dan bagaimana mengikatnya di tempat yang benar sehingga sama dengan gambarnya. Pada saat yang sama juga anak belajar konsep tentang berputar dan anak mengenal kosa kata baru. Anak juga diajar membilang angka 1-5 saat mengikat benang. Anak mengenal kosa kata baru dan mengenal alam yaitu daun lontar. 


\section{H. Tahap ta hab'bu}

Proses mewarnai kain tenun Sabu masih menggunakan bahan-bahan alam. Kain tenun sabu di dominasi oleh warna hitam, merah dan kuning. Warna hitam diambil dari pohon tarum/ biasa disebut dao yang dicampur dengan pinang kering, sirih kering dan kulit batang jambu air tua.

Warna merah dibuat dari akar mengkudu atau ka'bbo dan dicampur dengan batang kayu jambu air yang muda sebagai penguat warna.

Warna kuning dari kunyit.

Saat mencari bahan-bahan ini, anak biasa diajak oleh ama nya.

Saat menumbuk, menghaluskan bahan dan mencampur kedalam air, anak biasanya diajak ina nya.

Semua bahan-bahan yang di haluskan akan dimasak dan benang yang dikat akan dimasukan. Proses perendaman ini bisa memakan waktu sampai 2 hari.

Pada tahap ini akan kemampuan mengenal lingkungan alam di stimulasi. Anak mengetahui bahwa alam menyediakan banyak hal untuk dieksplore. Anak mengenal bahan-bahan yang bisa membuat air berwarna hitam, merah dan kuning. Anak mengetahui jika kulit jambu air dicampur dengan sirih dan pinang akan menghasilkan warna. Pada saat yang sama juga anak menambah kosa kata baru dengan mengenal nama-nama pohon yang di temui di hutan.

\section{Tahap ta none pe kemangu}

Tahap ini adalah benang yang sudah dimasak dan direndam akan di sampai kering.

Benang akan dijejerkan di atas batu atau jemuran bambu.

Tahap ini anak akan belajar tentang alam, yaitu proses pengeringan. Anak belajar bahwa matahari dan angin mampu menguapkan air dalam benang sehingga benang menjadi kering.

\section{J. Tahap ta hap'pu \& Tahap ke'jeri}

Ta ha'ppu adalah memutuskan ikatan di benang yang sudah kering. Sementara ke'jeri adalah mengatur di alat menenunnya.

Biasanya anak membantu saat melepaskan ikatan lontarnya.

Mengaturnya di alat tenun biasanya dilakukan oleh orangtua karena membutuhkan ketelitian.

Pada proses melepaskan ikatan benang motorik halus dan kasar anak di stimulus. Anak mampu membedakan rasa gesekan benang yang sudah di celup dan yang tidak.

\section{PENUTUP}

\section{A. Simpulan}

Orang Sabu tidak memiliki cara khusus untuk proses pembelajaran baik itu ketrampilan maupun nilai-nilai hidup pada anak-anak mereka yang masih berusia dini. Sebelum Semua itu dilakukan sejalan dengan mereka melaksanakan aktifitas kesehariannya. Saat bekerja misalnya, anak diajak ikut saat mereka ke ladang, menyadap nira juga menenun. Hal ini bukanlah aturan adat, akan tetapi ini seperti kesepakatan yang tidak tertulis, yang dilakukan dan disosilisasi turun temurun sehingga akhirnya menjadi sebuah kesepakatan adat nilainya mengikat. Salah satunya dalah anak perempuan sudah harus belajar tenun sejak kecil dan cukup mampu membantu orangtuanya menenun saat berumur 6 tahun.

Ada 8 tahap dalam menenun yang ternyata memiliki nilai-nilai stimulasi dini tumbuh kembang anak usia dini baik itu motorik kasar dan halus, stimulasi kemampuan membilang, kemampuan berbahasa dan kemampuan seni.

\section{B. Saran}

Berdasarkan hasil di atas, maka ada beberapa saran yang diberikan:

a. Membangkitkan potensi-potensi budaya lokal untuk membangun sebuah model pembelajaran yang kontekstual. 
b. Model pembelajaran di PAUD dapat di modifikasi atau diintegrasikan dengan potensi-potensi budaya seperti menenun.

c. Sosialisasi potensi-potensi budaya pada anak sejak dini memberi manfaat ganda, selain memperkenalka budaya menstimulasi kemampuan anak.

d. Studi ini merupakan studi awal untuk melihat salah satu potensi budaya di NTT khususnya pulau Sabu. Diharapkan ada studi-studi lanjutan untuk menggali lebih dalam mengenai potensi-potensi budaya.

e. Studi ini hanya melibatkan tokoh masyarakat Sabu yang sudah tinggal di Ibukota NTT, yaitu Kupang. Disarankan agar studi yang sama dilakukan langsung di Pulau Sabu dengan metode observasi dan wawancara.

Bornstein, M. H., \& Cote, L. (2004). "Mother's parenting cognitions in cultures of origin, scculturating cultures and cultures of destination". Child Development, 75, 21-235.

Baron, A. (2004). "Early childhood care and education in Africa: the case of Botsowa. Journal of Early Childhood Research, 2, 67-84

Dedalgo, B, M., \& Ford, L. (1998). "Parental Perceptions of child development among low income Mexican American Families". Journal of Child and Family Studies, 7, 469-481.

Duran, T. (2011). Boti, Demi Masa Lalu. Diambil kembali dari POS KUPANG: http://kupang.tribunnews.com/2011/0 2/05/-boti-demi-masa-lalu-

Gottfried A. E., Fleming. J. S., \& Gottfried, A. W. (1998). "The role of a cognitively stimulating home environment in child-ren's academic intrinsic motivation: Longitudinal study". Child Develop-ment, 69, 14481460.

\section{DAFTAR PUSTAKA}

Astuti, F. (2009). Efektivitas Permainan Tradisional untuk Meningkatkan Kreatifitas Verbal pada Masa Anak Sekolah, Skripsi, Surakarta: UMS

Bunga, B. (2012). "Pengembangan Pendidikan Karakter melalui permainan tradisional" Makalah disampaikan pada Seminar Himpunan Evaluasi Pendidikan Indonesia, Yogyakarta: UNY

Bunga, B. (2011). Laporan ECCE di Kab Belu. Save The Children

\section{Bungin, B. (2001). Metodologi penelitian} kualitatif. Jakarta: Rajagrafindo Persada

Gutman, L. M., \& Mcloyd, V. D. (2000). "Parents management of their children's education within the home, at school, and in the community: An examination of afican American Families living poverty". Urban Review, 32, 1-24

Iswinarti. (2008). "Nilai-nilai Terapiutik Per-mainan Tradisional Engklek pada Anak Usia Sekolah Dasar", Laporan Peneli-tian, Malang: UMM

Koentjaraningrat. (1972). Beberapa Pokok Antropologi Sosial. Jakarta: Dian Rakyat

Labre, B., Yohanes, H., \& Andreas, A. (2011). Laporan Pendampingan program PAUD di Kabupaten TTU. Child Fund Indonesia

Labre, B., \& Andreas, A. (2011). Laporan Assesment pendidikan dan pelatihan pengembangan PAUD di Kab Sikka. Word Vision Indonesia

Riwu, K. R. (2005). Orang sabu dan budayanya. Yogyakarta: Yogya Global Media 
Jurnal Parameter Volume 29 No. 2

DOI : doi.org/10.21009/parameter.292.04

P-ISSN : 0216-26IX

Seriati, Ni Nyoman (tidak bertahun). "Permainan Tradisional Jawa Gerak dan Lagu untuk Menstimulasi Ketrampilan Sosial Anak Usia Dini”. , Laporan Hasil Penelitian, PGPAUD.
Siegel, S. (1997). Statistik Non Parametrik Untuk Ilmu Sosial. Jakarta: PT. Gramedia Pustaka Utama. 